\title{
Research Article revision and Error Analysis (EA): Have Tunisian novice researchers learnt from their errors
}

\author{
Chokri Smaoui $^{1}$, Elhoucine Essefi ${ }^{2}$ \\ ${ }^{1}$ RU: DISCOURSE ANALYSIS. Faculty of Letters and Humanities of Sfax, Sfax, Tunisia \\ ${ }^{2}$ National Engineering School of Sfax, Road of Soukra, km 4 Zipcode3038, Sfax, Tunisia
}

Email address:

hocinsefi@yahoo.fr (E. Essefi)

\section{To cite this article:}

Chokri Smaoui, Elhoucine Essefi. Research Article Revision and Error Analysis (EA): Have Tunisian Novice Researchers Learnt from their Errors. International Journal of Language and Linguistics. Vol. 3, No. 1, 2015, pp. 16-21. doi: 10.11648/j.ijl1.20150301.13

\begin{abstract}
This work tried to see whether Tunisian novice researchers have taken advantage of their errors or not. By studying a case study in terms of Corpus Linguistics, it was found out that difficulties of Tunisian novice researchers lie in their unfamiliarity with error terminology and with the tradition of the corrective feedback. This lacuna is inherited from the Tunisian official programs, which have excluded this endeavour from their interests. Thus, Tunisian novice researchers could not profit from the corrective feedback either during their educational career or during the revision process of their Research Articles.
\end{abstract}

Keywords: Error Terminology, Error Analysis (EA), Corpus Linguistics, Corrective Feedback

\section{Introduction}

It was argued in previous works (e.g. Smaoui \& Sefi (forthcoming)) that Tunisian novice researchers, as a rule, have mastered neither the reading skills nor the linguistic features of the scientific discourse; as a result of this, their scientific products are more than likely to be replete with a variety of errors. Unlike the behaviorist scholars, cognitivists believe in the beneficial effects of errors on language learning. Accordingly, these products represent a fertile ground to apply the Error Analysis (EA) methodology. But cognitivists themselves link this beneficial effect to the capacity of the learners to profit from their errors. In this vein, this work aims to critically evaluate the study of errors in the Tunisian context. This work on errors spans the educational career and continues into the correction process of scientific products. In so doing, this work will answer the question whether Tunisian novice researchers have taken advantage of their errors or not.

\section{Method}

This work adopts the approach of Contrastive Linguistics (Stockwell and Martin, 1965); it is meant to simulate the weak version of the Contrastive Analysis Hypothesis (CAH) (Wardaugh 1970). The common point between this work and the weak version of the $\mathrm{CAH}$ lies in using a deductive approach. By analogy to the weak version of the $\mathrm{CAH}$, this work deduces from errors in a specific sample (Gallela et al. (2009)) the types of difficulties of Tunisian novice researchers with scientific writing. Furthermore, it will discuss their capacity to profit from correction of errors either during their educational career or during the revision process of their articles. Since it was noticed that most Tunisian novice researchers compile their research papers first in French, then, they translate them into English, Error Analysis (EA) will take into account the linguistic features used in the scientific discourse previously discussed and errors related to translation. Following the school of Corpus Linguistics (e.g., Conrad, 2002), errors will be also exemplified from a Tunisian scientific products recently published: a Research Article (Gallela et al., 2009) $(4,175$ words). As for the corpus used (Gallela et al. (2009)), compilation of Research Theses in English seems to be not quite common in the Tunisian scientific community. The corpus of this study is thus limited only to the first drafts of Gallela et al. (2009). Concerning Error Analysis (EA), Tunisian novice researchers are confronted with the number and the degree of seriousness of their errors during their educational career and during the revision process of their Research Articles. In this study, due to the difficulties to realize an actual experience of the corrective feedback during the educational career of Tunisian novice researchers, the 
investigation of its history will be done by discussing errors in the first draft of Gallela et al. (2009) before contacting any scientific journal. That is to say, we will simulate the case of a teacher providing correction to his student. The corrective feedback during the revision process will be done by discussing modifications in the following drafts of this paper after contacting a scientific journal.

\subsection{Controversies over Error Analysis and Corrective Feedback}

Before discussing the capacity of Tunisian novice researchers to profit from the corrective feedback, it is important that we shed light on the debate taking place between scholars concerning the corrective demarche as a whole. Actually, there is no agreement between scholars either on the efficiency of the corrective feedback or on the most effective method of Error analysis (e.g., Ferris, 2006; Yates and Kenkel, 2002, Ellis 2014). On the one hand, Ellis (2007) pinpointed five controversies surrounding corrective feedback in terms of both language pedagogy and second language acquisition; this suggestion of weakness is about the contribution of corrective feedback to second language acquisition, types of errors to correct, the person doing correction, the most effective type of corrective feedback and the best timing for corrective feedback. On the other hand, eventhough they recognized the complexity and difficulty of the demarche, several studies considered that different error correction techniques help improve linguistic accuracy (e.g., Yeh and Lo, 2009). For instance, Lee (1997) conducted a study to examine the hierarchy of difficulty of detection and correction of errors. By distinguishing between surface (spelling, grammar) and meaning (cohesion) errors, Lee (1997) sets three different conditions of errors: marked condition, slightly marked condition and unmarked condition. He also showed that students performed best in the marked condition and performed worst in the slightly marked and unmarked version. These findings confirmed that the corrective demarche is quite defendable; but students' failure in error correction lies in their failure in detecting errors. Accordingly, error correction techniques, which can help students detect and correct errors, are needed (cf. Smaoui 1993). Lee (1997) went further to suggest that students' performance in error correction itself can afford a useful source of information to help teachers formulate their error correction policy. For writing instruction, error correction and corrective feedback are important tasks for both teachers and students in many contexts. Although it is generally agreed that students expect teachers to correct written errors and teachers are willing to give them this correction (e.g., Lee, 1997; Schulz, 1996), the immediate concern of many teachers "is not so much to correct or not to correct" (Lee, 1997), but rather when and how to respond to what students write (Lee, 2003; Magilow, 1999; Yates and Kenkel, 2002).

\subsection{Error Analysis in Translation}

\subsubsection{Translation Errors}

Translation errors are different from errors that would occur in spontaneous native language production. In the case of second language learners, they may be mixed up with linguistic errors; their identification seems thus less evident. Accordingly, the model of analysing errors and translation assessment must be based on a combination of training in linguistics and in translation.

\subsubsection{Models of Error Analysis in Translation}

There is no unified framework to classify translation errors. Nevertheless, some attempts have been made to unify standards. For instance, the National Accreditation Authority for Translators and Interpreters in Australia (NAATI) proposed a marking system dealing with translation errors. Another attempt suggested by the American Translation Association (ATA) is intended for standard error marking and explanation of work done by professional translators. It pinpoints 22 types of errors, which may be summarized as follows: 1) Incomplete passage, 2) Illegible handwriting, 3) Misunderstanding of the original text, 4) Mistranslation into target language, 5) Addition or omission, 6) Terminology, word choice, 7) Register, 8) Too freely translated, 9) Too literal, word-for-word translation, 10) False cognate, 11) Indecision in word choice, 12) Inconsistent, 13) Ambiguity, 14) Grammar, 15) Syntax, 16) Punctuation, 17) Spelling, 18) Accents and other diacritical marks, 19) Case (upper case/lower case), 20) Word form, 21) Usage and 22) Style. With the flourishing of computing, in the case of Research Article compilation, some errors may be automatically avoided. As a matter of fact, typing on the computer saves students from making many errors and decreases the possibility of making others. For instance, the errors of illegible handwriting and spelling are totally avoided. Other errors of grammar, syntax, punctuation are minimized; in fact, the computer proposes automatic corrections to such errors. Given the fact that translating involves the skill of handling text and the combination of different sentences, it seems that this list needs to be improved in order to be a sufficient model in error grading. Accordingly, when discussing some errors in the first drafts of Gallela et al. (2009), this study will refer to Richards' taxonomy (1974) and Corder's taxonomy (1974) to deal with mixed errors.

\section{Results}

Recently, problems of second language students with error correction have been discussed. According to Lee (1997), second language students were often asked to correct grammatical errors, but seldom were they told to categorize them. But since Lee's (1997) research suggested that students' failure in error correction was mainly due to their failure in detecting errors, he claimed "recognizing the existence of errors" as a crucial variable in error correction. Similarly, in this study, results of error analysis are not a goal in themselves. Quite the reverse, the capacity of Tunisian novice researchers to understand and profit from this effort made either during their educational career or during the revision process of their Research Articles is the major goal. These results of studying errors must be confronted to the 
acquired skills concerning this deal of Error Analysis.

Note: $(*)$ means that the sentence is ungrammatical; $(* *)$ means that the sentence is grammatical but inappropriate.

\subsection{Corrective Feedback during the Educational Career}

Simulating the case of a teacher correcting his student, we can realise a situation of corrective feedback during the educational career by selecting some samples from Gallela et al.*, (2009. Actually, only one sentence (14 words) from Gallela et al.*, (2009) was enough to show how much errors are frequent in the scientific products of Tunisian novice researchers. There is no need to be highly coached in English to recognize that the following example contains errors: $\left(49^{*}\right)$ "the sandstones derived from sources on continental blocks came eventually from two tectonic settings*" (Gallela et al., $2009^{*}$ ); it may be corrected to become (49) "Sandstones derived from sources on continental blocks could theoretically come from two tectonic settings" (Gallela et al., 2009). In this example, the authors have committed many errors at the same time. First, the use of the determiner 'the' derived from the original text in French 'les sandstones'; such interference error (Richards, 1974) is classified as interlingual error; because such a distinction with plural nouns does not exist in French. This systematic (Corder, 1974), local error (Burt and kisparsky, 1972) is due to wordfor-word translation (ATA); it does not impede communication. But it can falsify the original meaning; because the authors in their minds meant the general case, and not the studied case as it is deduced from the example. The occurrence of such errors proves that the authors are quite influenced by their first language of science, French. Second, the use of the adverb 'eventually' also proves that they are influenced by French. This interference error is classified as overextension of analogy (Richards, 1974) resulting from a confusion between the false cognates (ATA) 'eventually' and 'éventuellement'. Actually, this systematic error (Corder, 1974) and global error (Burt and kisparsky, 1972) impedes communication by destroying the original meaning of the sentence. Third, the use of the verb 'came' is erroneous. Actually, unlike the two previous overt errors (Corder, 1974) which are easy to detect, this third error is covert (Corder, 1974). Apparently, the structure seems, and is really, grammatical. But the structure contains an error of appropriateness (Corder, 1974); this social error (Corder, 1974) concerns the linguistic features of the scientific discourse. Thus, to correct this error of style (ATA), the authors should have used the modal verb 'could'.

The problem here is not in such a correction of errors but in the capacity of Tunisian novice researchers to simulate the terminology of these errors. Actually, they have never been exposed to such a terminology. Thus, this correction is goodfor-nothing; since students lack the basics to profit from it. During the educational career, Tunisian students normally went through corrective feedback but they have not profited from this task. Because the big gap between teachers' and students' understanding of grammatical terms in relation to errors makes students struggle to apply teacher feedback to their writing. For instance, the study of the previous example shows, as it is noticed by Berry (1995), that Tunisian students are unfamiliar with the grammatical rules and the metalinguistic terminology related to errors. Actually, no course in the Tunisian official programs has discussed explicitly the terminology of errors. The situation becomes darker in the case of Tunisian novice researchers, because two other handicaps are added to their difficulties. On the one hand, their mastery of the scientific discourse is not well established to compile directly their scientific product in English. On the other hand, since they have never received translation courses during their educational career, they are not well coached in translation to use it in compiling their articles. The actual problem in the case of Tunisian novice reresearchers, hence, is not only being able to do correction of errors in the studied example, but also to be aware of these errors. Authors are not able to assimilate explanation about their errors concerning the compilation of the scientific discourse; they are more than likely to repeat the same errors in other papers; because they lack the minimum background about scientific English, translation and even general English.

\subsection{Corrective Feedback during the Revision Process of a Research Article}

Instead of using a standard text with errors implanted, Lee (1997) suggested the use of a student text, where errors occur naturally, to examine learners' performance in error correction. In the same vein, the revision process of drafts of Research Articles represents an opportunity for novice researchers to profit from the corrective feedback from people of high rank in the discipline. Once it is sent, a Research Article (RA) undergoes a long process of revision until it reaches gatekeepers' expectations. The initial drafting and revising of a scientific paper by researchers in response to feedback and criticism made scholars strongly emphasize the very nature of these writing processes as social action. The importance of this revision from the initial draft to the accepted version is twofold. First, the author acquires maturation and awareness of the scientific discourse. Second, the quality of the article increases. In this study about Tunisian novice researchers, this revision acquires a third importance: it shows many of their errors that may be discussed in the framework of their acquisition of English. But to benefit from this revision process, they must understand first the reasons behind the rejection of their papers and the necessary revision process to become accepted. Building on Knorr-Cetina's (1981) classification, Godsen (1995) recognized five major categories of revision process of a Research Article: deletion (-TD), addition (+TD), reshuffling of statements (CR), rhetorical machining (RMI) and language polishing (PL). Each of these categories will be exemplified from Gallela et al*, (2009).

\subsubsection{Deletion}

Deletion (-TD) is meant to remove technical detail or statements. The number of words in (RAs) is in advance assigned by the scientific journal; the author must make use 
of these words in relevant remarks. Actually, the overuse of words is encountered in the method section, when the Tunisian novice researchers use up their word in useless technical details about the method. But they must remember that they will be facing expert gatekeepers, who have a high mastery of such methods. As an illustration of this deletion we take the following sentence; (50**) "For the determination of grain size distribution, standard sieves from the series "AFNOR" (Association Française de Normalisation, that encompasses diameters ranging from $40 \mu$ to $2.5 \mathrm{~mm}$, were used**"(Gallela et al., 2009**). The author may omit the technical details about the abbreviation 'AFNOR' because it is well recognized by specialists that AFNOR series contains those sieves. Thus, the corrected form becomes (50) "For the determination of grain size distribution, standard sieves from the series "AFNOR" (Association Française de Normalisation), were used" (Gallela et al., 2009).

\subsubsection{Addition}

Addition (+TD) means to add technical details or statements. This lack of relevant information is especially encountered when introducing local settings or terminology. For example, Tunisian novice researchers of geology may cause their readers to be lost by introducing Tunisian local terminologies as standards. They forget that the readers might have never heard about Tunisia. For instance, example $(50 * *)$ "On the scale of the study area, the Early Cretaceous formations outcrop mainly along the range of North-South axis, and in the mountains situated east of Gafsa" (Gallela et al., 2009**) is incoherent; because the terminology 'NorthSouth axis' is a local terminology known only by Tunisian geologists. To be correct, it must become (50) "On the scale of the study area, the Early Cretaceous formations outcrop mainly along the range of the so-called North-South axis, and in the mountains situated east of Gafsa" (Gallela et al., 2009).

\subsubsection{Reshuffling of Statements}

Reshuffling of Statements (CR) is generally done at the level of clauses within the same sentence or at the level of whole sentences. Since Tunisian novice researchers deal with translation, the output structures may be contaminated by the original text Interference like in $\left(51^{*}\right)$ "The sedimentation was during the Barremian mainly continental in the Atlas western and central and became argillaceous to marly and thicker towards the Aurès Mountains in Algeria", (Gallela et al., 2009*). This mistranslation into target language (ATA) from the original text is due to transfer structures (Richards, 1974) of the French structure (Atlas occidental et central) to (Atlas western and central). This ambiguity about the position of adjective as Premodifier obliges researchers to use the so-called avoidance strategy (see, e.g. Smaoui 2010) with the manipulation of Postmodifiers of head nouns. The transfer structure is also noticed with the position of the adverbial of time (during the Barremian), which is located, uncommonly with English syntax, in the middle of the sentence. To correct this sentence, a complex sentence may be compiled in example (51) "During the Barremian, sedimentation was mainly continental in the western and central Atlas and became argillaceous to marly and thicker towards the Aurès Mountains in Algeria" (Gallela et al., 2009). Such skills of combining a complex and compound sentence are not reachable for all Tunisian novice researchers; in fact, these structures are taught only in the second year of general English.

\subsubsection{Rhetorical Machining}

Textual modifications reflect what Swales (1990) has referred to as the rhetorical machining (RMI) of scientific discourse. The revision process of Gallela et al. (2009) has proven that such a linguistic feature is missing, even for expert Tunisian authors. Thus, it is added with the progression of the revision process. This major category may be further subdivided into three basic orientations.

\subsubsection{Rhetorical Machining of Discourse Structure}

This kind of rhetorical machining deals with textual modifications, which relate to the rhetorical machining of discourse structure (RMdl). A primary resource here is the manipulation of the interrelated structures of Theme-Rheme and Given-New (Halliday, 1985). This category includes the usage of 'minimal' marked Themes as contextualizing frames (Gosden 1992), such as the use of 'in addition' in $(52 * *)$ "monocrystalline quartz grains are generally stretched and show undulatory extinction" to become rhetorically more efficient (52) "In addition, monocrystalline quartz grains are generally stretched and show undulatory extinction". Others may be useful to increase cohesion. To name but a few, one can quote some adverbs (here, furthermore, now), lexicalized markers of discourse organization (X will be discussed in the next section . . , as shown in Figure $1 .$. , the first is. . the second is . .., these are summarized ...), markers of contrast, (however, on the other hand, although ... ). Actually, this battery of machining tools does not lack in the mind of the Tunisian novice researcher; but its use necessitates a sort of pragmatic competence to appropriately use it.

\subsubsection{Rhetorical Machining of Claims}

Changes which relate to RA writers' claims (RMc) about their research and which therefore strongly reflect awareness of anticipated feedback from the academic community. As a general defining characteristic, this category includes the addition of a range of lexical hedging (it can be suggested that, it seems reasonable to conclude that . . . X may be interpreted as. ., it is likely that . . ., to our knowledge, possibly, certainly, probably). In addition, this category focuses on any textual modifications, which relate strategic hedging (this evidence leads us to conclude that . ., more details are required . . . precise measurement is difficult at this moment, these findings agree with Smith (6) ... . Rhetorical machining here thereby reflects increased degrees of writer visibility (Davies 1988; Gosden, 1993) and a more dynamic interactional stance as RA discourse progresses to its concluding Discussion. 


\subsubsection{Rhetorical Machining Related to Writers' Purpose}

Rhetorical machining which relates to RA writers' purpose (RMpl) and the expression of reasons for and results of research actions taken and conclusions reached. This category particularly contributes to the necessary "tightly regulated flow of reason" (Knorr-Cetina 1981) with the addition of "minimal" adjuncts such as therefore, consequently, accordingly, thus, or subordinate clauses, in order to . . . , because . . ., since . . . . As with all rhetorical machining of discourse, revisions in this category again indicate an increased awareness of audience expectations.

\subsubsection{Polishing of Language}

The final category of textual revisions concerns the polishing of language, generally below clause level. After being declared as 'Accepted with minor revision' by the scientific journal, the final version must be cleaned. This last category is naturally an important aspect in the final stages of the creation of 'successful' drafts, particularly for Non Native Speakers, because the high occurrence of careless mistakes may also cause rejection.

As a final conclusion of this analysis of the corrective feedback during the revision process of a Research Article, one can say that a rejected article represents a good opportunity to acquire mastery of the scientific discourse. But Tunisian novice researchers can run the risk of losing the advantages of this task, because the culture of the corrective feedback was not established in advance during their educational career. Moreover, as a further deficiency of Tunisian programs, varieties of revision process are not discussed. Sometimes, difficulties reach a crucial point, because Tunisian novice researchers lack the minimum requirement to be on the same wavelength with the scientific community; in such a case scientific journals advise them to contact a native speaker for a radical correction.

\section{Conclusion}

Due to their frail background in general English and their literacy of scientific discourse and error terminology, this work showed that Tunisian novice researchers are not able to profit from the corrective feedback of their teachers during their educational careers and comments of gatekeepers and reviewers during the revision process of their articles. The problem lies in the educational system. During their educational career Tunisian novice researchers should, by rights, acquired a formative approach; the passive students should be more attentive about the corrective feedback of their teachers. This dynamicity should also span during their career as researchers when dealing with the revision process of their Research Articles. Moreover, when giving their students feedback on their errors, teachers should take into account their previous English language instruction. Unfortunately, these requirements have not been satisfied. Tunisian students sometimes show signs of passivity; their intervention in the teaching process has been limited. In the face of this harsh reality, the scientific community finds itself sometimes obliged to tolerate errors in published documents of Tunisian researchers. From the corpus of this study, the following sample (32) "These sediments most likely accumulated in environments where current action was either weak or deposition was very rapid" (Gallela et al., 2009*) was published in spite of the errors that are noted in it.

\section{Corpus}

Gallala, W., Gaied, M.E., Essefi, E., Montacer, M., 2010. Pleistocene calcretes from eastern Tunisia: The stratigraphy, the microstructure and the environmental significance. Journal of African Earth Sciences 58, 445-456.

\section{References}

[1] Berry, R. (1995). Language teachers and metalinguistic terminology. Paper presented at the Third international conference on teacher education in second language teaching, Hong Kong, City University of Hong Kong, March 14-16, 1995.

[2] Burt, M. and kisparsky, S. (1972). Approach to Error Analysis'. In Richards, J. (Ed.). Error analysis: Perspectives on Second Language Acquisition. 172-188. Essex: Longman.

[3] Corder, S. (1974). 'Idiosyncratic Dialects and Error Analysis'. In Richards, J. (Ed.). Error analysis: Perspectives on Second Language Acquisition. 158-171. Essex: Longman.

[4] Davies, F. (1988). Reading between the lines: Thematic choice as a device for presenting writer viewpoint in academic discourse. Especialand, 9, 173-200.

[5] Ellis, R. (2007). Corrective Feedback in Theory, Research and Practice [Abstract]. Presented at the 5th international conference on ELT in China \& the 1st congress of chinese applied linguistics. Beijing, China: Beijing Foreign Language Studies University, May 17-20, 2007. $<\mathrm{http} / / / \mathrm{www}$. celea.org.cn/2007/edefault.asp $>\quad$ Retrieved 23.10.07.

[6] Ellis, R. (2014). The relevance of the 'implicit' vs 'explicit' distinction for language teachers. Paper presented at the second international conference of the Tunisian Association of Teachers of English (TATE), Tunis, Tunisia.

[7] Ferris, D. (2006). Does error feedback help student writers? New evidence on the short- and long-term effects of written error correction. In K. Hyland, \& F. Hyland (Eds.), Feedback in second language writing (pp. 81e104). Cambridge: Cambridge University Press.

[8] Gosden, H. (1993). Discourse functions of Subject in scientific research articles. Applied Linguistics, 14, 56-75.

[9] Gosden, H. (1995). Success in Research Article Writing and revision: A Social-Constructionist Perspective. Pergamon, 14, $37-49$

[10] Knot-r-Cetina, K. (1981). The manufacture of knowledge. Oxford: Pergamon Press.Gruyter.

[11] Lee, I. (1997). ESL learners' performance in error correction in writing: Some implications for teaching. System, 25(4), 465-477. International Journal of the Sociology of Language, 98, 67-100. 
[12] Magilow, D. H. (1999). Case study \#2: Error correction and classroom affect. Teaching German, 32(2), 125-129.

[13] Richards, J. (1974). 'A Non-Contrastive Approach to Error Analysis'. In Richards, J. (Ed.). Error analysis: Perspectives on Second Language Acquisition. 172-188. Essex: Longman.

[14] Schulz, R.A. (1996). Focus on form in the foreign language classroom: Students' and teachers' views on error correction and the role of grammar. Foreign Language Annals, 29, 343364 .

[15] Smaoui, Ch. (1993). Error Analysis: communicative concern as a major contributor to students' errors. Unpublished M.A. thesis. University of Kairaouan, Tunisia.

[16] Smaoui, Ch. (2010). Foreign language learners' ways of expressing 'difficult' concepts. In Tarchouna, N. (ed.), CrossCultural Dialogues: Proceedings of the English Department Conference, Faculty of letters \& Humanities, Sousse (7-9 December 2006): 131-151. Imprimerie Officielle de la République Tunisienne.

[17] Smaoui, Ch. \& Sefi, E. (forthcoming). Reading process as first stage of the publication industry: have Tunisian novice researchers acquired the appropriate reading skills to do a literature review? International Journal of Language and Linguistics.

[18] Stockwell, R.P., and Martin, J. W. (1965). The grammatical structure of English and Spanish. Chicago: University of Chicago Press.

[19] Swales, J.M. (1990). Genre analysis: English in academic and research settings. Cambridge, UK: Cambridge University Press.

[20] Yates, R. and Kenkel, J. (2002). Responding to sentencelevels errors in writing. Journal of Second Language Writing, $11,29-47$.

[21] Yeh, S., Lo J. (2009). Using online annotations to support error correction and corrective feedback. Computers \& Education, 52, 882-892.

[22] Wardaugh, R. (1970). The contrastive analysis hypothesis. TESOL Quarterly 4: 123-30. 